\title{
Fast and Energy-efficient Demulsification for Crude Oil Emulsions Using Pulsed Electric Field
}

\author{
$\operatorname{Bin} X u$ \\ College of Chemistry and Chemical Engineering, Binzhou University, Binzhou, 256600, China \\ E-mail: cnxubin@aol.com
}

doi: $10.20964 / 2017.10 .84$

Received: 18 June 2017 / Accepted: 23 August 2017 / Published: 12 September 2017

\begin{abstract}
The demulsification performance for crude oil emulsions using pulsed electric field with and without demulsifiers was studied to find a fast and energy-efficient way to separate oil and water. Demulsifiers with more branches is more effective in demulsification due to the increased penetrability of the demulsifiers, the dewatering rate of crude oil emulsions by AE 121 can reach up to $96.4 \%$ after 60 min. The optimal voltage, frequency and pulse duration ratio of the pulsed electric field for the electrodemulsification process is $5 \mathrm{kV}, 4 \mathrm{kHz}$ and 0.8 , respectively and a dewatering rate of $91.3 \%$ after 10 min can be obtained at this condition. There is good synergistic effect between demulsifier and pulsed electric field for the demulsification of crude oil emulsions. The demulsification process by demulsifier and pulsed electric field can save at least $50 \%$ demulsifier compared with the chemical demulsification while it can save $50 \%$ time and energy compared with the pulsed electric field demulsification process.
\end{abstract}

Keywords: demulsification, crude oil emulsion, demulsifier, pulsed electric field, synergistic effect

\section{$\underline{\text { FULL TEXT }}$}

(C) 2017 The Authors. Published by ESG (www.electrochemsci.org). This article is an open access article distributed under the terms and conditions of the Creative Commons Attribution license (http://creativecommons.org/licenses/by/4.0/). 